\title{
Host/nonhost status and genetics of resistance in barley against three pathotypes of Magnaporthe blast fungi
}

\author{
R. Aghnoum • C. Bvindi • G. Menet • B. D'hoop • J. L. N. Maciel • \\ R. E. Niks
}

Received: 21 July 2018/ Accepted: 16 May 2019/Published online: 7 June 2019

(C) The Author(s) 2019

\begin{abstract}
Blast disease, caused by the Magnaporthe oryzae/grisea species complex, occurs in a wide range of wild and cultivated gramineous plant species including rice, wheat and barley. We inoculated a collection of cultivated (Hordeum vulgare ssp. vulgare L.) and wild (ssp. spontaneum) barley accessions with M. oryzae Oryza pathotype (MoO), Triticum pathotype (MoT) and Pennisetum pathotype (MsP) to quantify the host status of barley, and to identify sources of blast resistance. Unlike wheat, the barley gene pool is rich with sources of complete and partial resistance against Magnaporthe. Cultivated barley appeared a nonhost to MsP, whereas wild barley showed some degree of susceptibility. All 153 tested rice accessions were resistant to the MoT isolate, suggesting that rice is nonhost to this pathotype.
\end{abstract}

Electronic supplementary material The online version of this article (https://doi.org/10.1007/s10681-019-2436-z) contains supplementary material, which is available to authorized users.

R. Aghnoum - C. Bvindi - G. Menet - B. D'hoop ·

R. E. Niks ( ()

Plant Breeding, Graduate School for Experimental Plant

Sciences, Wageningen University \& Research,

Droevendaalsesteeg 1, 6708 PB Wageningen, The

Netherlands

e-mail: rients.niks@wur.nl

J. L. N. Maciel

Embrapa Trigo, Rodovia BR 285, Passo Fundo, RS,

Brazil
Inoculation of L94/Vada and Vada/SusPtrit RIL mapping populations with $\mathrm{MoO}$ and/or MoT isolates of $M$. oryzae indicated one large effect QTL, designated as Rmoql, on the short arm of chromosome $7 \mathrm{H}$ against the MoT isolate PY 67.1 in both populations. Resistance in $\mathrm{L} 94$ to the $\mathrm{MoO}$ isolate was due to a different QTL, located at 5H. An association mapping panel of West European barley cultivars also suggested that most QTLs were pathotype specific. Six blast resistance genes found in the biparental and association mapping studies coincided with map positions of powdery mildew resistance genes viz. Mlt, Mla6, Mlg, mlo, Mlj, and Mlhb genes. Our QTL and association mapping analyses do not support the association of the mlo resistance gene with enhanced susceptibility to $M$. oryzae as reported in literature.

Keywords Association mapping - Barley · Blast disease $\cdot$ GWAS $\cdot$ Magnaporthe oryzae $\cdot$ mlo $\cdot$ QTL mapping

Present Address:

R. Aghnoum

Seed and Plant Improvement Research Department, Khorasan Razavi Agricultural and Natural Resources Research and Education Center, AREEO, Mashhad, Iran

Present Address:

B. D'hoop

Rijk Zwaan Breeding B.V., De Lier, The Netherlands 


\section{Introduction}

Blast disease on cultivated cereals is caused by the ascomycete fungus Magnaporthe oryzae, which was recently reported as a new species, separate from Magnaporthe grisea. It also causes the blast disease on wild grasses and rice (Couch and Kohn 2002). M. oryzae is one of the most harmful pathogens on rice (Oryza sativa), causing rice blast in many ricegrowing regions (Greer and Webster 2001; Yadav et al. 2017). The Triticum pathotype of M. oryzae (MoT), which causes blast disease on wheat (Triticum aestivum L.), was first identified in 1985 in the State of Paraná in Brazil and in 1996 it appeared in the Santa Cruz region of Bolivia, and subsequently was reported from south and south-eastern Paraguay, and central and southern Brazil and other regions in South America. In 2016 the first wheat blast outbreaks were reported from outside South America, from Bangladesh (Abu Sadat and Choi 2017; Cruz and Valent 2017). Therefore, blast is now considered a major threat to wheat production in warmer climate zones worldwide. Blast disease was reported on barley (Hordeum vulgare L.) under field conditions in Japan, Thailand and in Brazil (Kawai et al. 1979; Matsumoto and Mogi 1979; Sato et al. 2001; Lima and Minella 2003). Blast on barley appears to have a marginal economic impact until now. During recent years, blast has emerged as a serious disease in major pearl millet (Pennisetum glaucum) growing areas in India (Sharma et al. 2013).

M. oryzae (Pyricularia oryzae) differs from Magnaporthe grisea based on phylogenetic analysis using a multilocus gene genealogy of DNA sequences from actin, beta-tubulin, and calmodulin genes and based on interstrain fertility tests (Couch and Kohn 2002). Magnaporthe grisea (Hebert) Barr refers to the isolates of the fungus pathogenic on species of the crabgrass genus (Digitaria spp.). M. grisea and $M$. oryzae cannot be distinguished morphologically (Couch and Kohn 2002).

Most research on the host specificity of different pathotypes of Magnaporthe was based on a limited number of plant genotypes and pathogen isolates. The picture emerges that isolates of MoT are pathogenic on wheat, barley, rye and oat, but not on rice (Urashima et al. 1993). Isolates of M. oryzae collected from rice (Oryza pathotype: $\mathrm{MoO}$ ) were reported to be pathogenic on barley (e.g. Chen et al. 2003; Inukai et al.
2006; Sato et al. 2001; Urashima et al. 1993; Zellerhoff et al. 2006; Hyon et al. 2012), but barley is considered a nonhost to isolates of a putative novel Magnaporthe species closely related to $M$. grisea collected on the genera Pennisetum (fontaingrass) and Digitaria (crabgrass) (Zellerhoff et al. 2006), although exceptional barley accessions (particularly 'Nigrate') were reported to be susceptible to a wide range of Pyricularia/Magnaporthe taxa, including to Magnaporthe collected from Digitaria (Hyon et al. 2012).

In rice more than 100 blast resistance genes have been identified and many of them have been deployed in high-yielding rice cultivars as single dominant resistance $(R)$ genes (Yadav et al. 2017; Skamnioti and Gurr 2009). So far, 25 rice blast major resistance genes have been cloned and characterized (Yadav et al. 2017). Typically, resistance genes in blast resistant cultivars become ineffective within a few years after release due to the adaptation of the pathogen (Ballini et al. 2008; Babujee and Gnanamanickam 2000). Unlike the situation in rice, genes for resistance to blast appear to be uncommon in wheat (Cruz and Valent 2017). The large majority of wheat accessions is susceptible to the wheat blast pathogen (Urashima et al. 2004) and only a few sources of field resistance have been reported (Kohli et al. 2011; Zhan et al. 2008), and only seven resistance genes have been identified in that crop (Anh et al. 2015).

The occurrence and genetic basis of blast resistance in barley against various pathotypes of Magnaporthe is being investigated by few researchers and few major genes for resistance were mapped (Yaegashi 1988; Inukai et al. 2006; Nga et al. 2012; Tagle et al. 2016). Yaegashi (1988) reported the PHR-I gene as a single isolate-specific dominant gene conditioning blast resistance in two barley cultivars against a barley blast isolate. This gene, which is not mapped yet, was ineffective to another barley isolate, to a rice isolate and to a crabgrass (Digitariasp.) isolate, to which the barley cultivars were susceptible. Another dominant resistance gene, Rmol, located on chromosome $1 \mathrm{H}$, was reported by Inukai et al. (2006) to be effective against rice blast isolates. Recently, Nga et al. (2012) reported a novel gene on $7 \mathrm{H}$, designated as Rmo2, conferring blast resistance in barley to different hostspecific pathotypes of $M$. oryzae from rice, wheat, foxtail millet (Setaria italica), and finger millet (Eleusine coracana)) but ineffective to $M$. grisea from crabgrass (Digitaria sanguinalis). This work was 
possible by using the exceptional barley 'Nigrate' as crossing parent. This accession is highly susceptible to any pathotype subgroup of $M$. oryzae and $M$. grisea. More recently, Tagle et al. (2016) reported that the Rmo2 locus is also effective against an isolate of Pyricularia pennisetigena, a cryptic species in the $P$. oryzae/grisea species complex. In addition to that, several QTLs (quantitative trait loci) for quantitative resistance were mapped in barley (Inukai et al. 2006; Sato et al. 2001; Chen et al. 2003). One particularly interesting finding was, that the recessive loss-offunction mutant at the Mlo locus conferring resistance against all known isolates of Blumeria graminis f.sp. hordei enhanced susceptibility to rice isolates of $M$. oryzae (Jarosch et al. 1999, 2003; Jansen et al. 2007) and to several other facultative pathogens of barley (McGrann et al. 2014; Kumar et al. 2001; Király et al. 2002; Makepeace et al. 2007; Jansen et al. 2005). All reports on the role of mlo in enhancing the susceptibility or resistance against other pathogens than powdery mildew are based on a few barley lines/ cultivars or near-isogenic lines with different alleles of Mlo. In addition to mlo, co-localization of blast resistance QTLs with other powdery mildew resistance genes has been reported in a few studies (Chen et al. 2003; Inukai et al. 2006; Sato et al. 2001).

In this paper we determined the host status of barley to isolates of $M$. oryzae collected from rice, wheat and Pennisetum using a large collection of barley, including the wild ancestor Hordeum vulgare ssp. spontaneum, from different regions. This panel also contained material carrying the mlo gene. We also screened a panel of rice accessions to compare the host status of rice to the rice blast fungus with that to the wheat blast fungus. The barley panel identified two mapping populations from parents that contrasted in level of resistance to map the underlying genes for resistance. We investigated the genetic basis of blast resistance in these two RIL mapping populations and an association mapping population of West European barley cultivars to MoT and MoO isolates. One of these mapping populations segregated for the mlo gene, providing an opportunity to quantify its role in enhancing susceptibility to the blast pathogen. Finally, we investigated the inheritance of a complete resistance in an East African barley accession with complete resistance to M. oryzae.

\section{Materials and methods}

Plant materials

\section{Screens of plant collections for resistance}

We tested a panel of 109 accessions of spring barley (Hordeum vulgare L.), including some modern and old cultivars from various origins, landraces and some parental lines of available mapping populations and a few experimental barley lines developed at Plant Breeding of Wageningen University. Almost all these accessions were also tested by Atienza et al. (2004) for susceptibility to several heterologous rust species. In addition we tested a set of 45 accessions of wild barley (H. vulgare ssp. spontaneum) obtained from The Leibniz Institute of Plant Genetics and Crop Plant Research (IPK) in Gatersleben, Germany. Both panels were inoculated with a Triticum and an Oryza isolate of $M$. oryzae to determine the host status of barley to these two pathotypes. Fifty-three barley landraces, obtained from The Centre for Genetic Resources, the Netherlands (CGN) together with lines L94, Vada and SusPtrit and the same set of 41 accessions of wild barley were tested with a Pennisetum infecting isolate of a novel Magnaporthe species closely related to $M$. grisea (Zellerhoff et al. 2006) (MsP). The set of 53 landraces was used in an earlier study to identify a few accessions with some unusual partial susceptibility to the wheat powdery mildew fungus (Aghnoum et al. 2010). Two accessions of pearl millet, PI517021 and PI532750, were obtained from Plant Genetic Resources Conservation Unit, USDA-ARS to act as susceptible reference. A collection of 153 accessions of rice (Oryza sativa L.) was obtained from The International Rice Research Institute (IRRI). This set was selected by IRRI from a collection of 3000 accessions after excluding the accessions that were documented as modern breeding lines or improved varieties, and represents all five major variety groups based on Garris et al. (2005) (aromatic, aus, indica, temperate japonica and tropical japonica) and across all geographical regions of rice cultivation.

Each inoculation experiment was performed in three independent replications. For each accession the average score for infection phenotype over the three replications was used as value for the susceptibility level. 
Mapping of resistance genes

We observed that L94, Vada, SusPtrit, and CGN02857 showed contrasting infection phenotypes against a wheat isolate of M. oryzae at the seedling stage. L94 and SusPtrit were partially resistant, CGN02857 was almost immune and Vada was very susceptible. L94 is an Ethiopian landrace carrying the mlo gene for powdery mildew resistance (Jørgensen 1992), Vada is a modern West European barley cultivar, and SusPtrit is an experimental barley line with high susceptibility to non-adapted rust fungi (Atienza et al. 2004) and CGN02857 is an East African barley accession obtained from the CGN germplasm collection at Wageningen University and Research Centre. Two barley recombinant inbred line (RIL) populations, L94/Vada (L/V, 103 lines, skeletal map consists of 568 markers) (Qi et al. 1998) and Vada/SusPtrit (V/ S, 152 lines, skeletal map consists of 448 markers) (Jafary et al. 2006), an association mapping panel of West European two-row spring barley elite lines and cultivars $(n=139)\left(\right.$ Kraakman et al. 2004) and an $F_{2}$ population from the cross of CGN02857 $\times$ Vada (130 $\mathrm{F}_{2}$ plants), were used for genetic analysis of blast resistance at seedling stage.

Pathogen materials

A Triticum isolate of M. oryzae (MoT isolate PY67.1) was used to determine the host status of barley. This isolate and nine more MoT isolates (PY30.1, PY06001, PY06029, PY06037, PY06047, PY19.1, PY47.2, PY22.2, and PY41.2) were used to test the isolate specificity of the barley resistance against $M$. oryzae. These isolates were selected from a collection of 142 isolates of $M$. oryzae collected from wheat in different regions of Brazil and were kindly provided by the Embrapa Trigo, Brazil. Isolates PY67.1 and BR32 were used to map the genes for resistance of barley to the MoT. The latter isolate was provided by Dr U. Schaffrath, at the Institute of Plant Physiology (Bio III), RWTH Aachen University, Germany. GUY11, an isolate of $\mathrm{MoO}$ collected from rice at French Guiana and CD180, an isolate of MsP, a putative novel species M. spec. Pathogenic on Pennisetum sp., collected at Ivory Coast, were provided by CIRAD, Montpellier, France.

The isolates were maintained on dried filter paper in $\mathrm{a}-20{ }^{\circ} \mathrm{C}$ freezer and propagated on Oatmeal agar $\left(\right.$ Difco $\left.^{\mathrm{TM}}\right)$ before inoculation experiments. Detailed information on the fungal isolates is shown in Table S1.

Inoculation and phenotyping of the panels and populations

Four seeds of each barley accession were sown in compost soil in 40-cell plastic trays (cells $7 \times 7 \times 6 \mathrm{~cm}$ in size, four seeds per cell). Depending on the pathogen isolate, the respective host plants were included in each tray to monitor the efficiency of inoculation. For rice this was cv Sariceltik, for wheat it was cv Vivant, for pearl millet accessions PI517021 and PI532750. Plants were grown in a pathogen free greenhouse compartment at $18-20{ }^{\circ} \mathrm{C}$ with $16 \mathrm{~h}$ of light and a relative humidity of about $70 \%$. The fungal isolates were grown for 15 days on oatmeal agar at $25{ }^{\circ} \mathrm{C}$ under a 16: $8 \mathrm{~h}$ light: dark cycle. The source of light was long tubular fluorescent lamps. The $15 \mathrm{~d}$ old fungal cultures were scratched three days before inoculation using a sterile scalpel to stimulate conidiation. At the day of inoculation, conidia were harvested by pouring $5 \mathrm{ml}$ of sterile inoculation solution (Tufan et al. 2009) containing $0.25 \%$ (w/v) gelatine and $0.01 \%(\mathrm{v} / \mathrm{v})$ Tween 20 into the plates and gently scraping the surface of the media using a sterile glass rod. Then the conidial suspensions were filtered through a sterile cheese cloth and the spore density in the filtrate was adjusted by adding inoculation solution to result in $2 \times 10^{5}$ conidia per ml. Twelve days after sowing, one seedling was cut away from each cell and three seedlings from each accession were used for inoculation. The plant accessions were not randomized individually in the trays. For each 40 cell tray, $14 \mathrm{ml}$ of conidial suspension was sprayed onto the leaves. The inoculated plants were put first in a clear plastic bag to maintain a water-saturated atmosphere and then were covered using a black plastic bag to provide dark conditions. They were incubated in a greenhouse compartment at $25 \pm 1{ }^{\circ} \mathrm{C}$ for $12-14 \mathrm{~h}$. Then the black plastic bags and four hours later the clear plastic bags were removed. The plants were then placed in a greenhouse compartment at $25 \pm 1{ }^{\circ} \mathrm{C}$ with $16 \mathrm{~h}$ of light and a relative humidity of about $80 \%$. The infection phenotype was assayed five days after inoculation, based on the $0-5$ scoring scale suggested by Oh et al. (2002): ( $0=$ no visible reaction, $1=$ brown pinpoint spots, $2=$ small brown lesions, 
3 = intermediate lesions, $4=$ large lesions, $5=$ large coalesced lesions resulting in complete blighting of the leaf blades).

We performed limited histological observations from the interaction of CGN02587 (complete resistance) L94 (partial resistance) and Vada (high susceptibility) with the MoT isolate PY67.1. Leaf samples were collected at three time points, 14, 24 and 48 hpi (hours post inoculation) and were stained with 3,3-diaminobenzidine (DAB) (Aghnoum and Niks 2010). The stained samples were embedded adaxial side up in glycerol and viewed by white-light microscopy.

\section{QTL analysis}

The software package MapQTL, version 6 (https:// www.kyazma.nl) was used for QTL analysis. For regions in which the LOD value exceeded the value 3, the marker with the highest LOD score was selected as co-factor for multiple QTL mapping analysis (Jansen and Stam 1994) and the results of the restricted multiple-QTL (rMQM) model were used for reporting the QTLs. Markers with the highest LOD value above the threshold were used to declare the presence of a QTL. The position of the QTLs were determined first on the individual maps and then their positions were translated to the barley integrated genetic map on the basis of the position of their peak marker and the flanking markers (Aghnoum et al. 2010). QTLs found in different mapping populations for which the LOD-1 interval overlapped, were considered to be due to the same gene. QTLs were named "Rmoq" (reaction to $M$. oryzae, quantitative) followed by the QTL number, following the nomenclature used by Qi et al. (1998) for genes for quantitative resistance to barley leaf rust (Puccinia hordei). To check whether the QTLs found in this study co-localized with the already reported QTLs/genes for blast resistance in other studies, we compared the map position of the peak marker of QTLs in the barley integrated map and defined the colocalization of QTLs when the peak marker of the reported QTL/gene mapped within the LOD-1 interval of the QTL in our integrated map.

\section{Association mapping}

The association panel of European spring barley cultivars was already deployed and described by
Kraakman et al. (2004, 2006). The panel originally had been genotyped by 236 AFLP markers that were polymorphic across the cultivars. For 128 of those AFLP markers the map position was known. Additionally, the panel was genotyped with 11 SSR markers (Kraakman et al. 2006). The resulting marker set showed 25 gaps ranging from 10 to $>30 \mathrm{cM}$ in the genetic map. For the position of the gaps, a total of 27 SSR markers were selected from Varshney et al. (2007) and tested across the cultivars to find polymorphic SSR markers to reduce the size and number of gaps. Details of SSR marker loci including SSR motif, PIC value and primer sequences are presented in Table S2, and were derived from Varshney et al. (2007). The PCR products were visualised on a LICOR4200 DNA sequencer. Closely linked markers should have correlated allele values in the association panel. Therefore, after placing the new SSR markers on the map, we checked for the correlations of allele values of markers that were adjacent in the map of Kraakman et al. (2004, 2006). This resulted in some markers not to be significantly associated with any other markers. They were removed. Other markers had to be repositioned to another location in the linkage groups. The 11 previous and 21 additional SSRs markers were scored as dominant markers $(0 / 1)$ based on the present allele and their name was based on their DNA amplicon size which resulted in 110 dominantly scored SSR alleles. These were used to reduce the number and size of gaps in the integrated linkage map. Compared to the original integrated map, the new map shows a better coverage of the genome and contained fewer and smaller gaps than the map used by Kraakman et al. (2006) (Table S3). In the original integrated map an estimated total of $207 \mathrm{cM}$ genetic area was beyond $10 \mathrm{cM}$ of the nearest marker. In the present map this was reduced to an estimated total of $95 \mathrm{cM}$.

Before association mapping, a standard quality control to the marker data was done. Not more than $25 \%$ of missing marker scores was allowed per sample and per marker, which resulted in removal of 30 markers (or alleles in case of the SSRs). The resistance data were combined with the available marker data and association analysis was performed with FaSTLMM (Factored Spectrally Transformed Linear Mixed Models), an algorithm for genome-wide association studies (Lippert et al. 2011). Significance of association ( $p$ value) and the effect of each marker on 
the trait values were calculated. Markers with $p$ value $<0.05$ are considered as significant associations. We considered two different associated markers as one QTL if their position on the integrated map (Aghnoum et al. 2010) is located within $5 \mathrm{cM}$ from each other.

Kraakman et al. (2004, 2006) checked for possible subpopulation structure in this panel of accessions, applying a cluster analysis, a correspondence analysis, and an analysis based on a Bayesian model. These analyses did not suggest a distinct population substructure.

Genetic analysis of the complete resistance in CGN02857 barley accession

To study the inheritance of wheat blast resistance in CGN02857, an East African barley accession, an $\mathrm{F}_{2}$ population from the cross of CGN02857 $\times$ Vada was developed. The parental cultivars, $F_{1}$ hybrid and 130 plants of an $\mathrm{F}_{2}$ population were inoculated with PY 67.1, a wheat isolate of $M$. oryzae. Plants were inoculated and scored in the same way as described above.

\section{Results}

Variation in response to blast pathogens in cultivated and wild barley

The majority of cultivated and wild barley accessions showed a compatible interaction (infection phenotype $2-5$, Figure S1) with different levels of susceptibility to the MoT isolate as well as to the $\mathrm{MoO}$ isolate (Table 1, Table S4). Our results suggest that $H$. vulgare ssp. spontaneum tends to be more susceptible than $H$. vulgare ssp. vulgare. The highly susceptible accessions (infection phenotype 4-5) showed typical water soaked blast lesions that later enlarged and coalesced resulting in complete blighting of the leaves (Fig. 1b). Seventy (to MoT) and forty-one (to MoO) percent of accessions (wild and cultivated) were partially resistant (infection phenotype 2-3), since they developed separated or merged brown coloured small lesions, mostly surrounded by a necrotic border. Compared to the MoT isolate the MoO isolate tended to give a higher infection phenotype on barley.

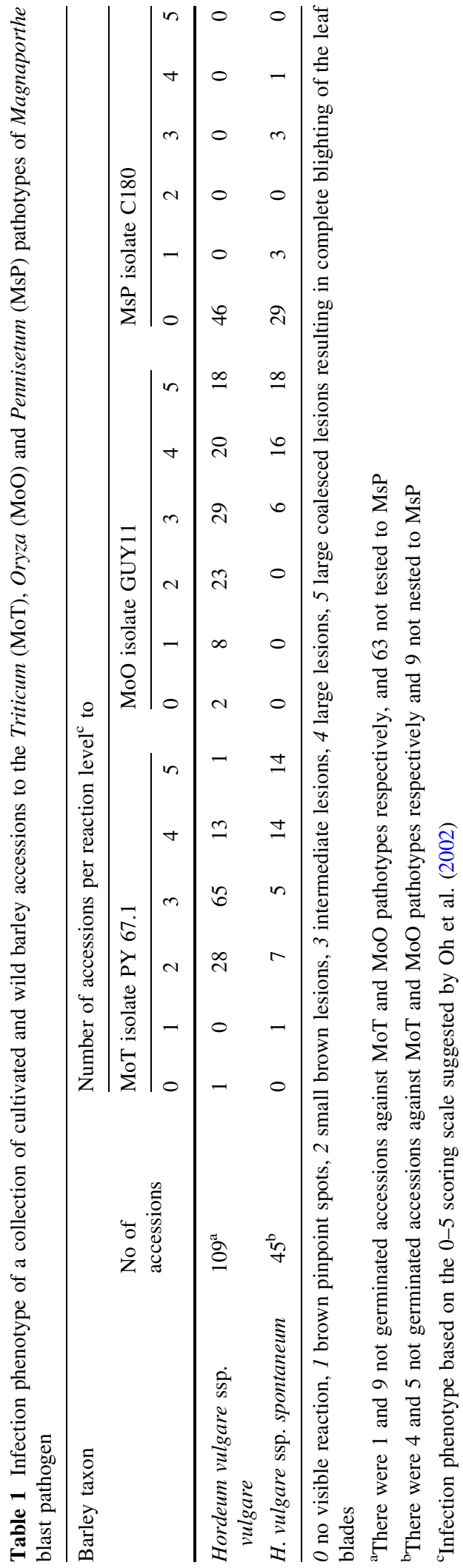




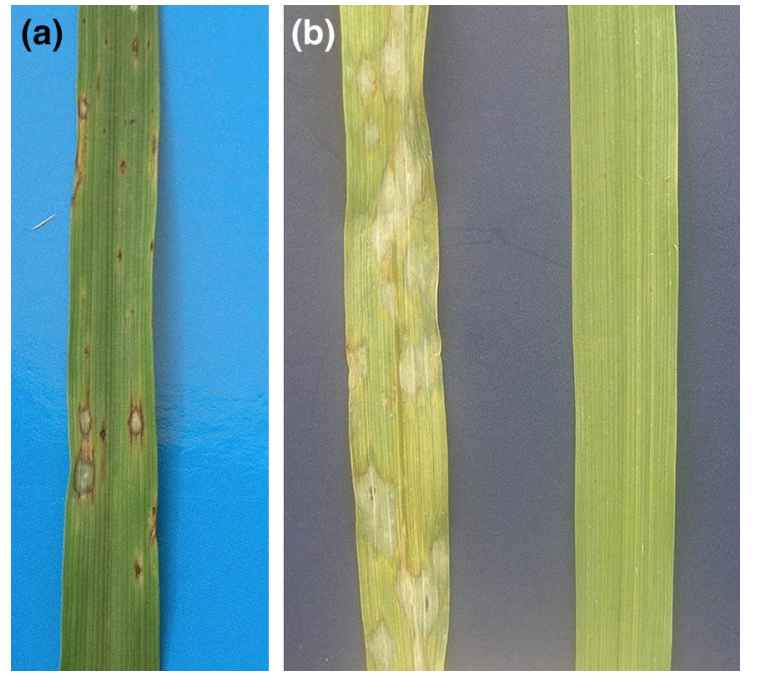

Fig. 1 a Partially resistant barley line L94 (infection phenotype 2) showing separated or merged brown coloured small lesions, mostly surrounded by a necrotic border. Barley accession SusPtrit showed a similar infection phenotype; b left, typical water soaked blast lesions in the compatible interaction on barley cv. Vada (infection phenotype 5), right, incompatible interaction on CGN02857 (infection phenotype 0), both 5 days after inoculation with the Triticum pathotype of Magnaporthe oryzae (PY 19.1 isolate). (Color figure online)

One and seven percent of accessions showed an incompatible interaction to the MoT and the $\mathrm{MoO}$ isolate, respectively, and produced no visible lesions or only small pinpoint brown necrotic spots (infection phenotype $0-1$ ). One of those completely resistant accessions was CGN02587 (scale value 0, Fig. 1b). L94 and SusPtrit were medium resistant to MoT isolate PY67.1 (scale value 2, see Fig. 1a) and Vada was very susceptible to this isolate (scale value 5 , Fig. 1b). The 50 barley cultivars averaged a bit more susceptible than the 53 landraces to MoT isolate PY67.1 (average infection phenotype 3.1 vs. 2.7, significant in two-tailed $t$ test $p<0.01$ ), but were not significantly different to the MoO isolate GUY11 (Table S4) (average infection phenotype score $3.0 \mathrm{vs.}$ 3.2) (Table S4). Our screening data also showed that the majority of mlo-carrying genotypes were partially resistant to the Triticum and/or the Oryza pathotypes of M. oryzae (Table 2, Table S4). The mlo genotypes Prestige, Odin, Sultan and L94 showed a medium to high level of resistance to both pathotypes (Table S4).

All 57 accessions of $H$. vulgare ssp. vulgare tested against the Pennisetum pathotype (MsP) isolate CD180 were fully immune showing no macroscopic symptoms suggesting that the cultivated barley is a nonhost to this infecting form. However, there was variation in response of the wild barley accessions against the MsP isolate (Figure S2). Three accessions showed brown pinpoint spots (infection phenotype 1) and four accessions showed small to large lesions resembling the compatible infection phenotypes 2-4 (Table S5). According to our data, H. vulgare ssp. spontaneum is a near-nonhost or marginal host to the Pennisetum pathotype of the blast fungus. This is an example of some intermediate (non)host status, as was reviewed by Niks (1987).

Histological observation of complete and partial resistance to blast pathogen MoT in barley

The infections of MoT isolate PY67.1 on the completely resistant line, CGN02587, were characterized by small brown pin-point spots that were hardly visible to the naked eye. On partially resistant lines L94 and SusPtrit this isolate formed small to medium sized lesions surrounded by a necrotic area. On the highly susceptible parent, Vada, the infections were characterized by large water-soaked lesions resulting in complete blighting of the leaf blades. Histological observations of CGN02587, L94 and Vada showed that in none of the accessions appressorium formation was associated with plant cell response (Fig. 2a-c). In CGN02587, hypersensitive reaction of the epidermal cells was observed at 24 and 48 hpi (Fig. 2d, g), indicated by whole cell accumulation of $\mathrm{H}_{2} \mathrm{O}_{2}$. In L94, some infection units were already stopped at $24 \mathrm{hpi}$ in association with a hypersensitive reaction (Fig. 2e) and the hypersensitive reaction spread to the mesophyll cells adjacent to the invaded epidermal cells (Fig. 2h). Hypersensitive reaction of epidermal cells was not observed in the very susceptible $\mathrm{cv}$ Vada (Fig. 2f). At 48 hpi large numbers of collapsed cells were observed in the mesophyll of Vada (Fig. 2i). This indicates successful growth of the blast fungus in mesophyll cells, which normally is associated with cellular disorganisation leading to the water soaked blast lesions (Zellerhoff et al. 2006).

Pathotype and isolate-specificity of resistance in barley-M. oryzae interaction

Evaluation of the barley collection against the Triticum and Oryza pathotypes showed evidence that 
Table 2 Infection phenotypes of 18 barley accessions to isolates of Triticum (MoT), Oryza (MoO) and Pennisetum (MsP) pathotypes of Magnaporthe blast fungus showing the isolate specificity of resistance in some accessions

\begin{tabular}{|c|c|c|c|c|c|c|c|c|c|c|c|c|}
\hline \multirow[t]{2}{*}{ Accessions } & \multicolumn{10}{|c|}{ MoT } & \multirow{2}{*}{$\begin{array}{l}\text { MoO } \\
\text { GUY11 }\end{array}$} & \multirow{2}{*}{$\begin{array}{l}\text { MsP } \\
\text { CD180 }\end{array}$} \\
\hline & 67.1 & 19.1 & 6037 & 6047 & 6001 & 629 & 20.2 & 22.2 & 41.2 & 30.1 & & \\
\hline Ab 14 Köln & 2 & 1 & $* \mathrm{c}$ & 1 & 3 & $*$ & $*$ & 3 & 3 & 3 & 1 & $*$ \\
\hline Apex $(m l o)^{\mathrm{a}}$ & $* \mathrm{~b}$ & 1 & 1 & 3 & 5 & 3 & 3 & 4 & 3 & 3 & $*$ & $*$ \\
\hline Cebada Capa & 3 & 2 & 3 & 3 & 4 & 3 & 4 & 4 & 4 & 4 & 3 & $*$ \\
\hline CGN00558 & 1 & 1 & 1 & 1 & 2 & 2 & 3 & 3 & $*$ & 2 & 4 & 0 \\
\hline CGN02424 & 2 & 2 & 2 & 1 & 2 & 3 & 3 & 2 & 2 & 2 & 2 & 0 \\
\hline CGN02857 & 0 & 0 & 0 & 0 & 1 & 0 & 2 & 0 & 1 & 0 & 1 & 0 \\
\hline DOM & $* \mathrm{~b}$ & 3 & 4 & 3 & 4 & 5 & 5 & 5 & 5 & 4 & $*$ & $*$ \\
\hline Henni $(m l o)^{\mathrm{a}}$ & $* \mathrm{~b}$ & 5 & 4 & 4 & 4 & 4 & 5 & 4 & 4 & 4 & $*$ & $*$ \\
\hline $\mathrm{L} 94(m l o)^{\mathrm{a}}$ & 2 & $*$ & 1 & 1 & 3 & 2 & 2 & 2 & 2 & 2 & 2 & 0 \\
\hline Meltan & $* \mathrm{~b}$ & 2 & 2 & 2 & 3 & 3 & 3 & 3 & 3 & 3 & $*$ & $*$ \\
\hline Morex & 3 & 4 & 5 & 5 & 4 & 5 & 5 & 4 & 4 & 4 & 2 & $*$ \\
\hline Nure & 3 & 3 & 4 & 1 & 4 & 4 & 5 & 5 & 4 & 4 & 2 & $*$ \\
\hline Prisma & 4 & 1 & 2 & 3 & 3 & 2 & 3 & 2 & 3 & 3 & 5 & $*$ \\
\hline Prominent & 2 & 0 & 1 & 1 & 2 & 1 & 2 & 1 & 2 & 1 & $*$ & $*$ \\
\hline Steptoe & 3 & 4 & 4 & 4 & 4 & 4 & 5 & 5 & 5 & 5 & 3 & $*$ \\
\hline SusPtrit & 2 & 2 & 2 & 2 & 4 & 2 & 3 & 3 & 3 & 4 & 4 & 0 \\
\hline Tremois & 3 & 2 & 2 & 1 & 4 & 3 & 3 & 3 & 3 & 4 & $*$ & $*$ \\
\hline Vada & 4 & 5 & 5 & 5 & 5 & 5 & 5 & 5 & 5 & 5 & 5 & 0 \\
\hline
\end{tabular}

Data represent the infection phenotypes based on the 0-5 scoring scale suggested by Oh et al. (2002)

a mlo carrying cultivars

${ }^{b}$ Not germinated in the first inoculation experiment with PY 67.1 isolate but included in the list since these genotypes represent the parents of available mapping populations in our laboratory

${ }^{c} *$ Not included or not germinated

barley is at seedling stage about equally susceptible to MoT as to MoO isolates (Table 1), but there was clear isolate-specificity (Table 2). Some accessions, for instance Reggae and Haisa, showed resistance to isolate PY67.1 of MoT but susceptibility to isolate GUY11 of the MoO. In contrast, other accessions, for instance Ragtime and Gunhild, showed susceptibility to MoT but resistance to the MoO isolate (Table S4).

We selected 18 barley accessions that showed different responses, from full resistance to high susceptibility to the MoT isolate PY67.1 and tested with nine more MoT isolates to determine whether their reaction is isolate-specific or not (Table 2). Some cultivars like Nure, Tremois, Prisma and Apex were susceptible to some and resistant to other isolates, suggesting isolate specific resistance. The barley landrace CGN02424, originating from India (Table 2 and Table S4) showed a high level of partial resistance to 10 tested MoT isolates and also to the only $\mathrm{MoO}$ isolate tested. CGN02857, an East African landrace, showed only small lesions (infection phenotype 2) to isolate PY20.2 and was completely resistant to nine other MoT isolates and also to the MoO isolate. Some relatively modern barley cultivars, like Vada and Steptoe, showed high susceptibility to almost all tested isolates. Two MoT isolates (PY06001 and PY20.2) tended to produce higher infection levels than the other tested isolates. Our results indicate that sources of isolate-specific and of isolate-nonspecific resistance to MoT are both present in the barley gene pool.

Host status of rice to the Triticum pathotype of $M$. oryzae

A large majority of 153 rice accessions were (near-) immune to the MoT isolate PY67.1, showing no 
CGN02587
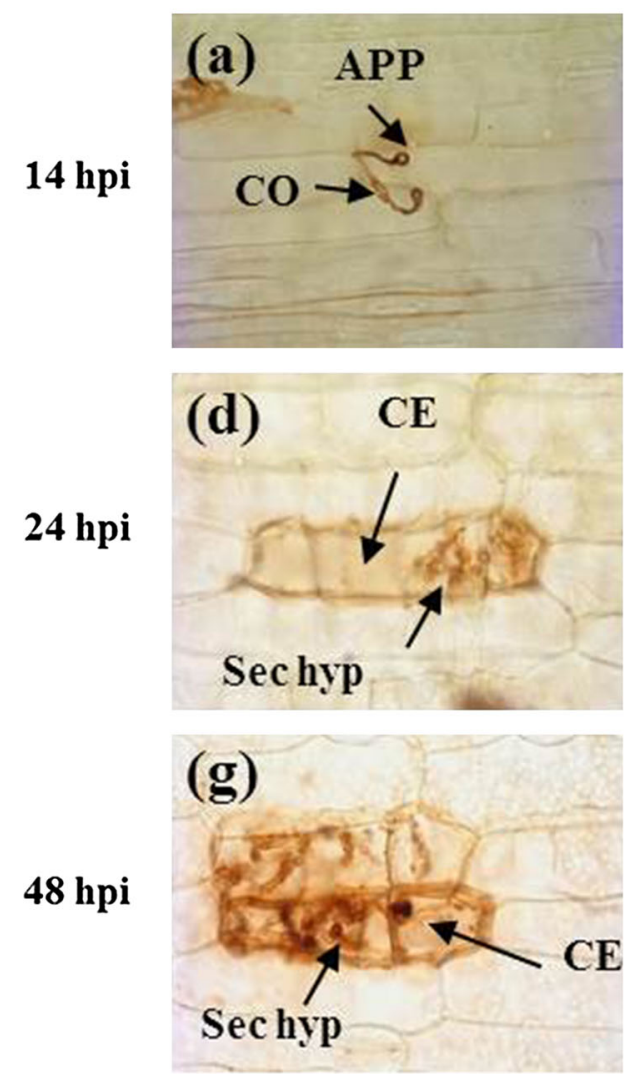

L 94
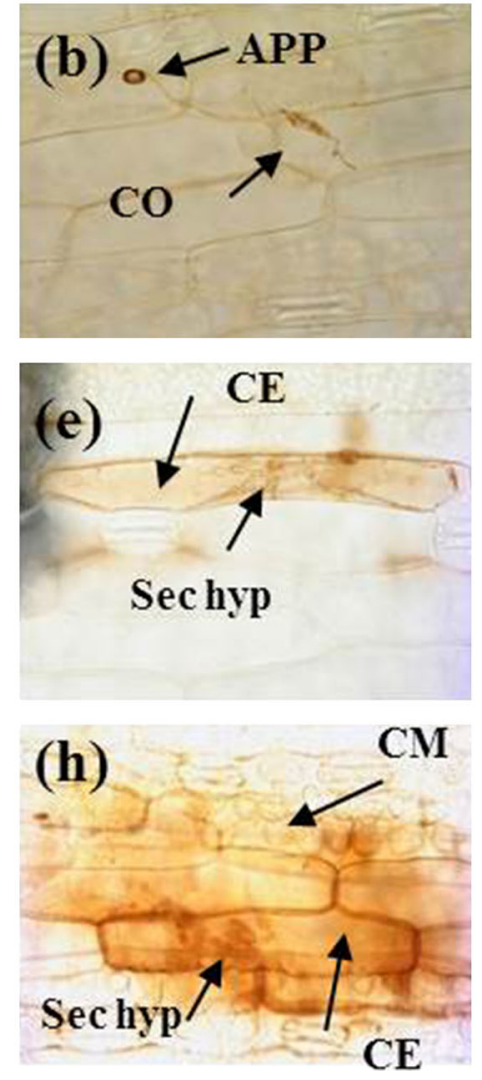

Vada
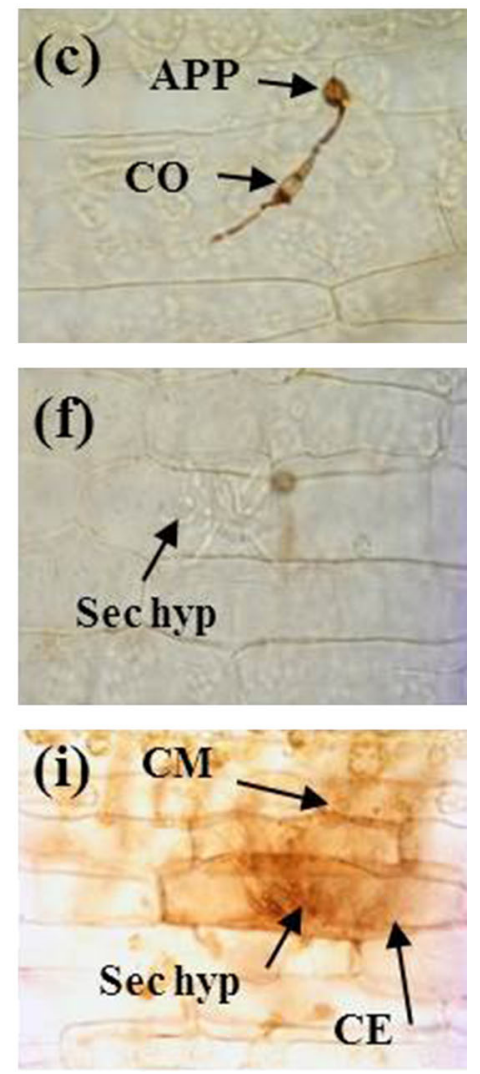

Fig. 2 Histological responses of three barley accessions, CGN02587 (complete resistance) L94 (partial resistance) and Vada (high susceptibility) inoculated with the Triticum pathotype (isolate PY67.1) of Magnaporthe oryzae. a-c Appressorium formation without plant cell defense response. $\mathbf{d}-\mathbf{g}$ Invasive or secondary hyphae associated with $\mathrm{H}_{2} \mathrm{O}_{2}$ accumulation throughout the epidermal cell, indicating a hypersensitive cell death

symptoms or a few small pin point necrotic flecks (Table S6). On none of the tested rice accessions the typical blast lesions of a compatible interaction developed. In 13 accessions the necrotic flecks covered more than $50 \%$ of the leaf area suggesting that penetration events might have elicited a hypersensitive reaction. Our data indicate that rice is a nonhost to MoT. reaction (HR). f Formation of secondary hyphae without plant defense response. $\mathbf{h}$ Secondary hyphae growing in multiple epidermal cells associated with the collapse of adjacent mesophyll cells. i Secondary hyphae associated with death of the mesophyll cells. APP appressorium, $C O$ conidium, $C E$ collapsed epidermal cell, $C M$ collapsed mesophyll cells, Sec hyp secondary hyphae

Inheritance of complete and partial resistance in some barley cultivars

\section{QTLs against wheat blast}

The contrasting degree of susceptibility between L94 and SusPtrit (both partially resistant) and Vada (very susceptible) (Table S4) prompted us to map the inheritance of the resistance in the already existing mapping populations $\mathrm{L} / \mathrm{V}$ and $\mathrm{V} / \mathrm{S}$ to MoT isolate PY67.1, and for L/V also to MoT isolate BR32 and $\mathrm{MoO}$ isolate GUY11. All populations showed a continuous segregation for blast infection phenotypes (Fig. 3a-d). In two cases (L/V with PY67.1 and BR32) the segregation was bimodal (Fig. 3a, c). In the 

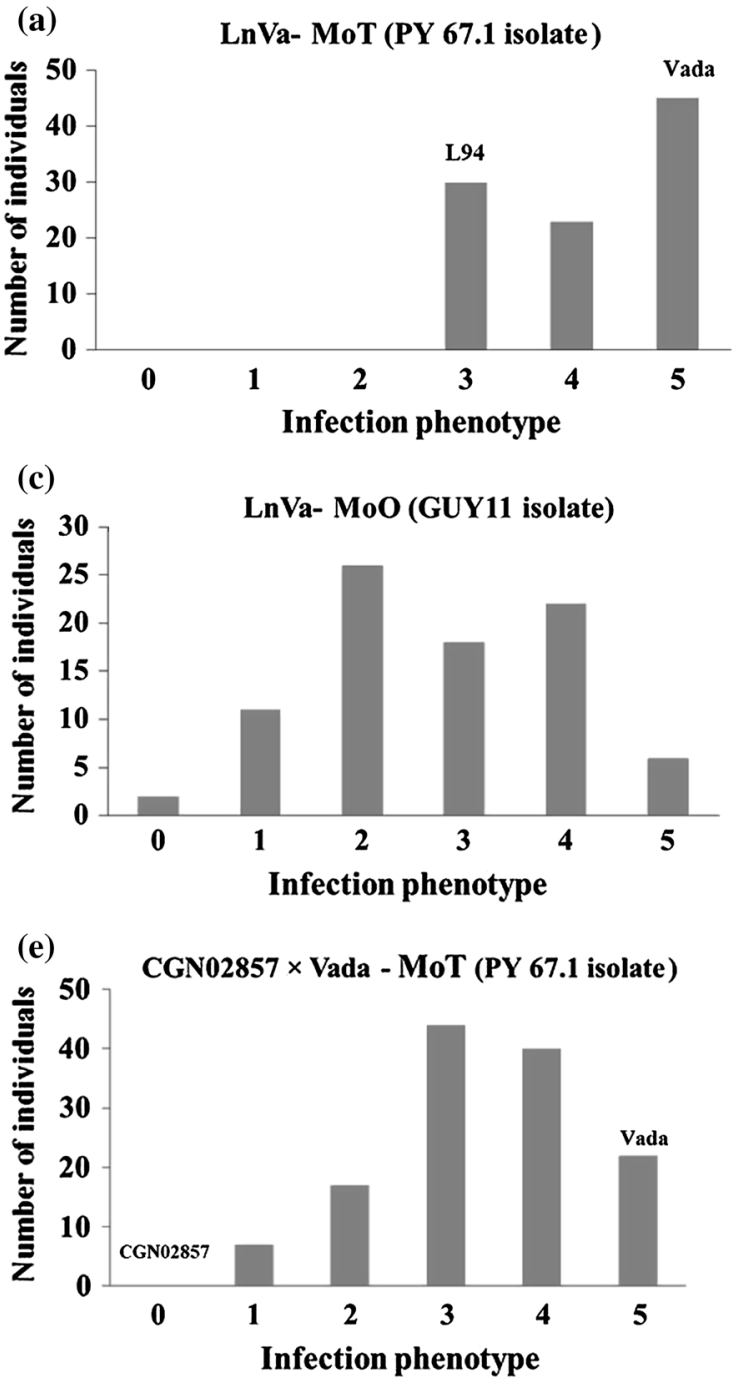

Fig. 3 Histograms of the frequency distribution of blast infection phenotypes in L/V and V/S RIL populations, in F2 populations derived from CGN02857 $\times$ Vada and the

mapping populations no substantial transgressive segregation was observed, neither towards resistance, nor towards susceptibility.

In both $\mathrm{L} / \mathrm{V}$ and $\mathrm{V} / \mathrm{S}$ mapping populations one large effect QTL mapped on the short arm of chromosome $7 \mathrm{H}$ against the MoT isolate PY67.1 (Table 3). The resistance alleles of this gene were contributed by L94 and SusPtrit, respectively. The peak markers of the QTL in V/S and in L/V were only $0.6 \mathrm{cM}$ apart in the integrated map of Aghnoum et al. (2010) and therefore SusPtrit and L94 are very likely to share the same gene for partial resistance to wheat blast. SusPtrit was (b)

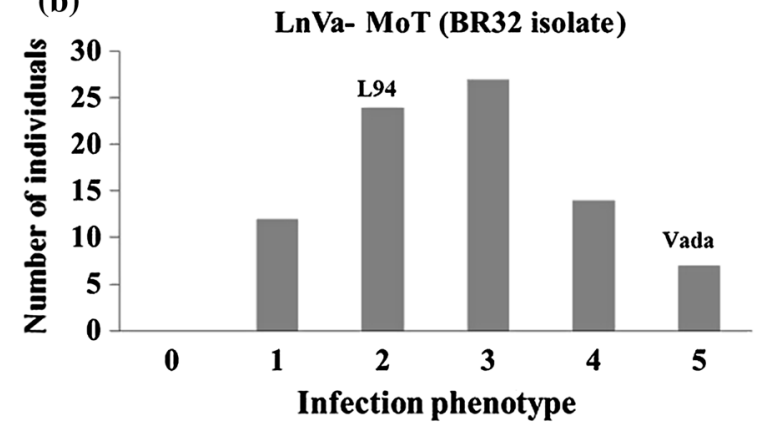

(d)

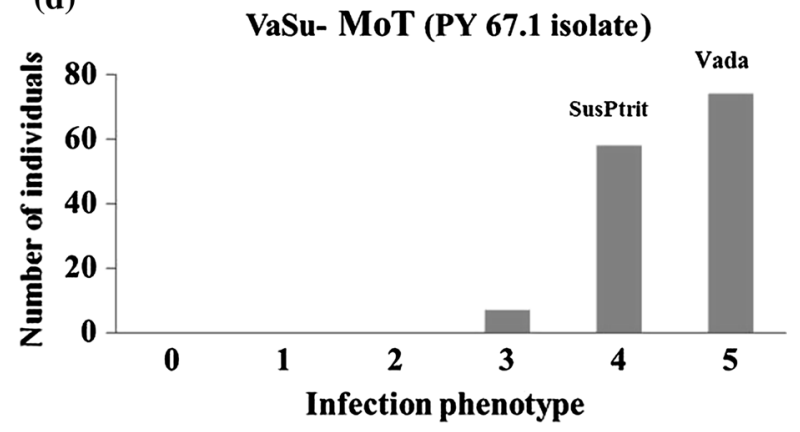

(f)

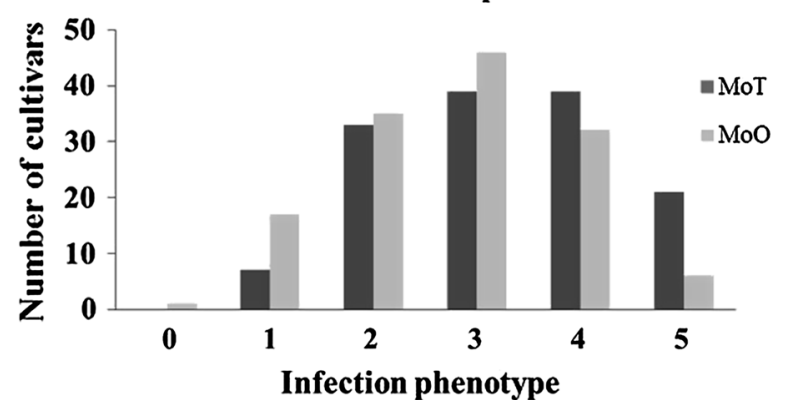

Association panel at the seedling stage against the Triticum pathotype (MoT isolate PY67.1) and/or the Oryza pathotype (MoO isolate GUY11) of M. oryzae

derived from L100, Nigrinudum, and Menelik, three land race lines from Ethiopian origin, as L94 is (Atienza et al. 2004), which may explain the shared resistance gene between L94 and SusPtrit. This QTL, which was designated as Rmoq1, accounted for $67 \%$ and $56 \%$ of the phenotypic variation in $\mathrm{L} / \mathrm{V}$ and $\mathrm{V} / \mathrm{S}$ populations respectively (Table 3 ). Rmoql was confirmed in the $\mathrm{L} / \mathrm{V}$ population phenotyped with the second MoT isolate, BR32. Comparison of the map position of the peak marker of Rmoql with the already reported QTLs/genes in literature suggested that Rmoql co-localized with Rmo2, a gene conferring 
Table 3 Summary of QTLs mapped at seedling stage for resistance against the Triticum (MoT) and Oryza (MoO) pathotypes of Magnaporthe oryzae

\begin{tabular}{|c|c|c|c|c|c|c|c|c|c|}
\hline \multirow[t]{2}{*}{ Population } & \multicolumn{2}{|l|}{ M. oryzae } & \multirow[t]{2}{*}{ QTL } & \multirow[t]{2}{*}{ Chr } & \multirow[t]{2}{*}{ Position $^{\mathrm{a}}$} & \multirow[t]{2}{*}{ Peak marker } & \multirow[t]{2}{*}{ LOD } & \multirow[t]{2}{*}{$\%$ Expl. $^{\mathrm{b}}$} & \multirow[t]{2}{*}{ Donor $^{\mathrm{c}}$} \\
\hline & Pathotype & Isolate & & & & & & & \\
\hline $\mathrm{L} / \mathrm{V}$ & MoT & PY 67.1 & Rmoq1 & $7 \mathrm{H}$ & 5.0 & E33M55-508 & 24.1 & 67.8 & L94 \\
\hline $\mathrm{L} / \mathrm{V}$ & MoT & BR32 & Rmoq1 & $7 \mathrm{H}$ & 5.0 & E33M55-508 & 10.8 & 44.9 & L94 \\
\hline $\mathrm{L} / \mathrm{V}$ & MoT & BR32 & Rmoq2 & $1 \mathrm{H}$ & 58.1 & P15M53-163 & 3.6 & 9.9 & Vada \\
\hline $\mathrm{L} / \mathrm{V}$ & $\mathrm{MoO}$ & GUY 11 & Rmoq3 & $5 \mathrm{H}$ & 115.4 & E42M48-282 & 7.7 & 30.5 & L94 \\
\hline $\mathrm{V} / \mathrm{S}$ & MoT & PY 67.1 & Rmoql & $7 \mathrm{H}$ & 5.6 & E42M51-232 & 24.6 & 56.3 & SusPtrit \\
\hline
\end{tabular}

${ }^{\text {a }}$ Position of the peak marker in the barley integrated map in cM (Aghnoum et al. 2010)

${ }^{\mathrm{b}}$ The proportion of the phenotypic variance explained by the QTL

${ }^{\mathrm{c}}$ Donor of the resistance allele

resistance in barley against pathotypes of $M$. oryzae from Setaria, Oryza, Eleusine, and Triticum (Nga et al. 2012).

In addition to Rmoql on $7 \mathrm{H}$, one more QTL (Rmoq2) was found in L/V, located on chromosome $1 \mathrm{H}$, against the BR32 isolate. This QTL accounted for around $10 \%$ of the phenotypic variation and the resistance allele was contributed by the susceptible parent, Vada. The mlo locus $(4 \mathrm{H}$, position $111.3 \mathrm{cM})$ in the $\mathrm{L} / \mathrm{V}$ population did not appear to contribute to the variation in infection level.

\section{QTLs against rice blast}

The frequency distribution of resistance phenotypes in the L/V population against the rice isolate (GUY11) showed a continuous and slightly bimodal distribution (Fig. 3c). One single QTL was mapped against the rice isolate GUY11on the long arm of chromosome $5 \mathrm{H}$ (Table 3). The resistance allele of the QTL was contributed by L94, and explains $30 \%$ of the phenotypic variation. None of the three detected QTLs were effective to both the wheat and the rice blast isolates.

Segregation analysis of the resistance phenotype in CGN02857

Despite the immunity of CGN02857 and than in an high input site like our $\mathrm{C} 2$ of the $\mathrm{F}_{1}$ hybrids and the high susceptibility of Vada, the seedlings of the $F_{2}$ of CGN02857 $\times$ Vada segregated quantitatively for infection phenotype by the wheat pathotype (Fig. 3e). This suggests that either few genes with intermediate effect or many genes with smaller effects confer the wheat blast resistance in CGN02857 at seedling stage.

Association mapping of genes for resistance to MoT and MoO isolates

\section{Association of markers with blast resistance}

The majority of the modern European barley cultivars in the panel were susceptible (infection phenotype $3-5)$ to MoT (71\%) and/or MoO (61\%) pathotypes at seedling stage (Fig. 3f). Nine percent of the cultivars were resistant to both pathotypes and $39 \%$ of cultivars showed a pathotype- or isolate-specific type of resistance. Table 4 gives a summary of AFLP and SSR markers significantly associated with resistance to the $\mathrm{MoT}$ and $\mathrm{MoO}$ isolates at seedling stage. Eighteen markers were associated with resistance against the MoT isolate of which nine markers had a known position on the integrated map. These nine associated markers indicate six different QTLs, markers at 5 or less $\mathrm{cM}$ distance being considered to indicate the same QTL. The indicated QTLs were located on chromosomes 2H (one QTL), 3H (two QTLs), 4H (one QTL) and 5H (two QTLs). Thirteen markers were associated with resistance against the $\mathrm{MoO}$ isolate of which eleven markers had a known position on the integrated map. These eleven associated markers represent ten different QTLs and were located on chromosomes $1 \mathrm{H}$ (one QTL), 3H (three QTLs), 4H (four QTLs), and 5H (two QTLs). The AFLP marker E38M54-367, on chromosome $3 \mathrm{H}$ at $63.2 \mathrm{cM}$, was the only marker allele that was associated with infection phenotype for 
Table 4 Markers in the association mapping panel (139 barley cultivars) that were significantly $(p$ value $<0.05)$ associated with resistance against the Triticum and Oryza pathotypes of Magnaporthe oryzae

\begin{tabular}{|c|c|c|c|c|c|c|c|}
\hline \multirow[t]{2}{*}{ Marker } & \multirow[t]{2}{*}{ QTL name ${ }^{\mathrm{a}}$} & \multirow[t]{2}{*}{ Chomosome } & \multirow[t]{2}{*}{ Position $^{\mathrm{b}}(\mathrm{cM})$} & \multicolumn{2}{|c|}{ Triticum pathotype } & \multicolumn{2}{|c|}{ Oryza pathotype } \\
\hline & & & & $p$ value $^{\mathrm{c}}$ & Effect $^{\mathrm{d}}$ & $p$ value & Effect \\
\hline GBMS062_127 & Rmoq10*** & $1 \mathrm{H}$ & 25 & & & 0.01 & -0.31 \\
\hline Bmac0134_173 & & $2 \mathrm{H}$ & 7.9 & 0.01 & 0.55 & & \\
\hline Bmac0134_142 & Rmoq4 & $2 \mathrm{H}$ & 7.9 & 0.02 & -0.45 & & \\
\hline E37M33-160 & & $2 \mathrm{H}$ & 12 & 0.02 & -0.77 & & \\
\hline E38M54-367 & $R m o q 5 *$ & $3 \mathrm{H}$ & 63.2 & 0.05 & 0.15 & 0.02 & 0.17 \\
\hline E37M33-238 & $\operatorname{Rmoq11*}$ & $3 \mathrm{H}$ & 69.8 & & & 0.05 & 0.19 \\
\hline Bmag0225_168 & $R \operatorname{Roq} 6^{*}$ & $3 \mathrm{H}$ & 86.8 & 0.04 & -0.19 & & \\
\hline Bmag0225_147 & & $3 \mathrm{H}$ & 86.8 & 0 & 0.43 & & \\
\hline Bmag0606_118 & Rmoq12 & $3 \mathrm{H}$ & 112.5 & & & 0 & 0.72 \\
\hline HVM040_162 & Rmoq13 & $4 \mathrm{H}$ & 32.3 & & & 0.01 & -0.34 \\
\hline E37M33-191 & Rmoq14** & $4 \mathrm{H}$ & 56.9 & & & 0.05 & 0.14 \\
\hline E45M55-142 & & $4 \mathrm{H}$ & 65 & & & 0.04 & 0.3 \\
\hline E42M32-179 & Rmoq7* & $4 \mathrm{H}$ & 65 & 0.05 & -0.23 & & \\
\hline E45M55-212 & Rmoq15*** & $4 \mathrm{H}$ & 107.3 & & & 0.02 & -0.22 \\
\hline E42M48-087 & Rmoq16 & $5 \mathrm{H}$ & 76.4 & & & 0.03 & -0.33 \\
\hline Bmag0223_160 & Rmoq17** & $5 \mathrm{H}$ & 88 & & & 0.04 & 0.19 \\
\hline Bmag0223_173 & & $5 \mathrm{H}$ & 88 & & & 0.02 & -0.8 \\
\hline E42M32-250 & Rmoq8* & $5 \mathrm{H}$ & 126 & 0.02 & 0.34 & & \\
\hline E39M61-272 & Rmoq9 & $5 \mathrm{H}$ & 157.1 & 0.03 & -0.49 & & \\
\hline E38M50-242 & & unm. & - & 0.01 & -0.58 & & \\
\hline E38M50-332 & & unm. & - & 0.02 & 0.39 & & \\
\hline E42M32-211 & & unm. & - & 0.04 & 0.23 & & \\
\hline E42M32-228 & & unm. & - & 0.01 & 0.44 & & \\
\hline E42M32-271 & & unm. & - & 0.04 & 0.52 & & \\
\hline E35M48-170 & & unm. & - & 0.04 & -0.31 & & \\
\hline E35M54-071 & & unm. & - & 0.02 & -0.42 & & \\
\hline E38M54-159 & & unm. & - & 0.03 & -0.66 & & \\
\hline E42M32-273 & & unm. & - & 0.03 & 0.35 & & \\
\hline E38M55-100 & & unm. & - & & & 0.04 & 0.54 \\
\hline E42M32-178 & & unm. & - & & & 0.02 & 0.25 \\
\hline
\end{tabular}

${ }^{\mathrm{a}}$ It is indicated whether within $5 \mathrm{cM}$ distance a gene for blast resistance $(*)$, powdery mildew resistance $(* *)$ or resistance to both pathogens $(* * *)$ has been reported in literature (see Table 5 for details)

${ }^{\mathrm{b}}$ Horizontal lines separate marker positions that map more than $5 \mathrm{cM}$ units apart, and therefore are considered to be associated with different QTLs

${ }^{\mathrm{c}}$ According to FaST-LMM (Factored Spectrally Transformed Linear Mixed Models) (Lippert et al. 2011)

${ }^{\mathrm{d}}$ The effect of each marker allele on the resistance phenotype was calculated as the average phenotypic score of cultivars carrying the "presence" allele $(=1)$ minus the average phenotypic score of the cultivars that did not carry that allele, or did not produce an amplification product $(=0)$. The values are on the basis of single allele dose effects. So, the contrast between homozygous genotypes should be double the effect presented here

unm. unmapped 
both isolates. For a locus on $4 \mathrm{H}$ at $65 \mathrm{cM}$ one AFLP marker was linked to a gene for resistance to the MoT isolate, the other to a gene for resistance to the $\mathrm{MoO}$ isolate. Probably the two AFLP markers are linked with different alleles of the resistance gene, each with a different specificity, and these contrasting combinations occur in different subsets of the panel. There was a low correlation in infection phenotype against the two forms in the association panel (Figure S3, $r=0.25)$. The QTL positions found in the association panel (Table 4) were different from the QTL positions found in the two biparental mapping populations (Table 3). Eight QTLs that were indicated by the association study to be associated with blast resistance coincided with already reported QTLs for blast resistance in literature (Tables 4, 5 and S7).
Coincidence of blast resistance QTL with powdery mildew resistance genes

Six blast resistance genes found in the biparental and association mapping studies (Tables 3 and 4) mapped within a $5 \mathrm{cM}$ distance from powdery mildew resistance genes in the integrated map. Rmoql, the major effect QTL mapped in both $\mathrm{L} / \mathrm{V}$ and $\mathrm{V} / \mathrm{S}$ populations against the wheat isolates, is located at the top of linkage group $7 \mathrm{H}$ in our integrated map within a $5 \mathrm{cM}$ distance from MWG851a, an RFLP marker that cosegregates with powdery mildew resistance locus mlt (Schönfeld et al. 1996). Therefore, Rmoql may be allelic with the recessive mlt mildew resistance gene. Locations of five QTLs mapped in the association panel coincided with Mla6, Mlg, mlo, Mlj and Mlhb mildew resistance genes (Table 5). The putative blast resistance QTL located in the vicinity of the mlo locus

Table 5 Co-localization of blast associated markers with blast resistance QTLs and powdery resistance loci reported in literature

\begin{tabular}{|c|c|c|c|c|c|}
\hline \multirow[t]{2}{*}{ Marker $^{1}$} & \multirow{2}{*}{$\begin{array}{l}\text { QTL } \\
\text { name }\end{array}$} & \multicolumn{2}{|c|}{ Blast isolate to which QTL was effective } & \multirow{2}{*}{$\begin{array}{l}\text { Mildew } \\
\text { resistance locus }\end{array}$} & \multirow[t]{2}{*}{ References } \\
\hline & & In our study ${ }^{\mathrm{a}}$ & In reference & & \\
\hline Bmac0134_142 & Rmoq4 & PY67.1 & TR306 $\%$ oryza pathotype & Mlhb & $\begin{array}{l}\text { Chen et al. (2003) and Pickering et al. } \\
\text { (1995) }\end{array}$ \\
\hline GBMS062_127 & Rmoq10 & GUY11 & $\begin{array}{c}\text { Baronesse/oryza and } \\
\text { barley pathotype }\end{array}$ & Mla6 & $\begin{array}{l}\text { Kongprakhon et al. (2009) and } \\
\text { Aghnoum et al. (2010) }\end{array}$ \\
\hline E37M33-238 & Rmoq11 & GUY11 & BCD47/oryza pathotype & & Inukai et al. (2006) \\
\hline E38M54-367 & Rmoq5 & $\begin{array}{l}\text { PY67.1 and } \\
\text { GUY11 }\end{array}$ & TR306/oryza pathotype & & Chen et al. (2003) \\
\hline Bmag0225 & Rmoq6 & PY67.1 & BCD47/oryza pathotype & & Inukai et al. (2006) \\
\hline E37M33-191 & Rmoq14 & GUY11 & & Mlg & Kurth et al. (2001) \\
\hline E45M55-142 & Rmoq7 & GUY11 & $\begin{array}{l}\text { Baronesse/oryza } \\
\text { pathotype }\end{array}$ & & Kongprakhon et al. (2009) \\
\hline E42M32-179 & Rmoq7 & PY67.1 & $\begin{array}{l}\text { Baronesse/oryza } \\
\text { pathotype }\end{array}$ & & Kongprakhon et al. (2009) \\
\hline E45M55-212 & Rmoq15 & GUY11 & TR306/oryza pathotype & mlo & $\begin{array}{l}\text { Chen et al. (2003) and Aghnoum et al. } \\
\text { (2010) }\end{array}$ \\
\hline Bmag0223 & Rmoq17 & GUY11 & & $M l j$ & Schönfeld et al. (1996) \\
\hline E42M32-250 & Rmoq8 & PY67.1 & TR306/oryza pathotype & & Chen et al. (2003) \\
\hline E33M55-508 & Rmoq1 & $\begin{array}{l}\text { PY67.1 and } \\
\text { BR32 }\end{array}$ & Various isolates of grasses & $m l t$ & $\begin{array}{l}\text { Nga et al. (2012) and Schönfeld et al. } \\
\text { (1996) }\end{array}$ \\
\hline
\end{tabular}

${ }^{\mathrm{a}}$ See Table 4 for position and association with resistance to blast. PY67.1 and BR32 are Triticum pathotypes, GUY11 is an Oryza pathotype

${ }^{\mathrm{b}}$ Donor of the resistance allele

${ }^{\mathrm{c}}$ Mapped in two biparental mapping populations in the present work (Table 3) 
Table 6 Mean infection phenotype score ${ }^{\mathrm{a}}$ of RILs from the L/V population carrying different alleles of mlo and Rmoq1 against isolate PY67.1 of the Triticum pathotype of Magnaporthe oryzae

\begin{tabular}{llll}
\hline Genotype & \multicolumn{2}{l}{ Major effect QTL at 7H } & Average $^{\mathrm{f}}$ \\
\cline { 2 - 3 } & Rmoq1 & rmoq1 & \\
\hline mlo & $3.10^{\mathrm{b}}$ & $4.58^{\mathrm{c}}$ & 3.84 \\
Mlo & $3.53^{\mathrm{d}}$ & $4.45^{\mathrm{e}}$ & 3.99 \\
Average $^{\mathrm{g}}$ & 3.31 & 4.51 & \\
\hline
\end{tabular}

${ }^{\mathrm{a}}$ Based on the $0-5$ scoring scale (Oh et al. 2002) from three independent inoculation experiments

${ }^{\mathrm{b}} \mathrm{RILs}$ 15, 20, 27, 35

${ }^{\mathrm{c}} \mathrm{RILs} 17,23,33,80$

${ }^{\mathrm{d}}$ RILs 13, 21, 31, 29

${ }^{\mathrm{e}}$ RILs 14, 19, 32, 88

${ }^{\mathrm{f}}$ Difference in severity for $m l o-M l o$ not significant

${ }^{\mathrm{g}}$ Difference in severity for Rmoq1-rmoq1 significant

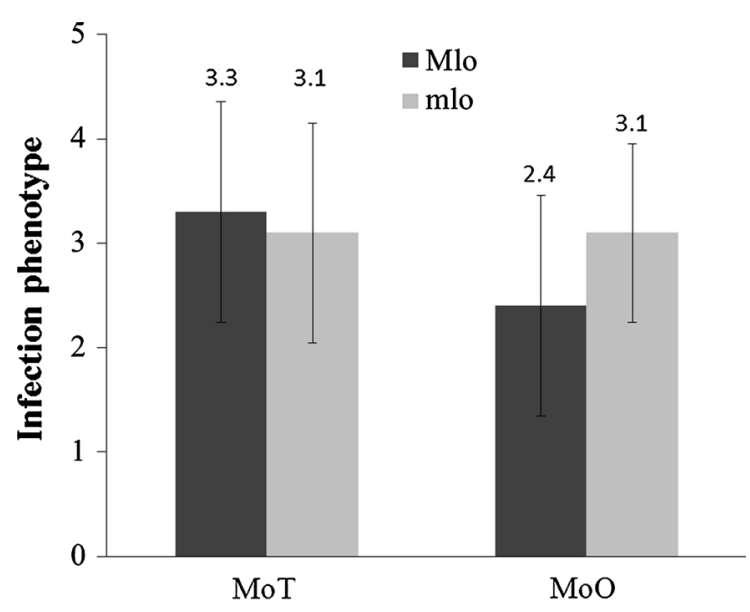

Fig. 4 Infection level of a set of 97 modern European barley cultivars carrying Mlo wild-type and 40 cultivars carrying mlo mutant alleles against the Triticum pathotype (MoT isolate PY67.1) and/or the Oryza pathotype (MoO isolate GUY11) of $M$. oryzae at the seedling stage. Difference between the means are statistically significant by the $t$ test at $\alpha=0.05$

with an effect on blast suggested a reduced rather than an increased blast infection on accessions carrying the mlo allele. This direction of the association does not confirm previous reports that the mlo allele would promote blast infection (Jarosch et al. 1999). Forty out of the 139 modern European barley cultivars used in our association mapping study carry the mlo mutant
Table 7 Mean infection phenotype score ${ }^{\mathrm{a}}$ of RILs from the L/V population carrying different alleles of mlo and Rmoq1 against isolate GUY11 of the Oryza pathotype of Magnaporthe oryzae

\begin{tabular}{llll}
\hline Genotype & \multicolumn{2}{l}{ Major effect QTL at $7 \mathrm{H}$} & Average $^{\mathrm{f}}$ \\
\cline { 2 - 3 } & Rmoq1 & rmoq1 & \\
\hline$m l o$ & $3.13^{\mathrm{b}}$ & $2.56^{\mathrm{c}}$ & 2.84 \\
Mlo & $2.63^{\mathrm{d}}$ & $3.06^{\mathrm{e}}$ & 2.84 \\
Average $^{\mathrm{g}}$ & 2.88 & 2.81 & \\
\hline
\end{tabular}

${ }^{\mathrm{a}}$ Based on the $0-5$ scoring scale (Oh et al. 2002) from three independent inoculation experiments

${ }^{\mathrm{b}}$ RILs 15, 20, 27, 35

${ }^{\mathrm{c}}$ RILs 17, 23, 33, 80

${ }^{\mathrm{d}}$ RILs 13, 21, 31, 29

${ }^{\mathrm{e}}$ RILs 14, 19, 32, 88

${ }^{\mathrm{f}}$ Difference in severity for $m l o-M l o$ not significant

${ }^{\mathrm{g}}$ Difference in severity for Rmoq1-rmoq1 not significant

allele (Mlo-page, https://www.crpmb.org/). Average blast infection phenotype in 97 cultivars carrying the Mlo allele and of 40 carrying the mlo allele, indicated that the infection phenotype in the mlo cultivars tended to be slightly lower than in the Mlo cultivars for the MoT isolate PY67.1 and significantly higher for the MoO isolate GUY11 (Fig. 4). We also re-tested a subset of 16 RILs from the L/V mapping population for infection phenotype of blast infection to determine the effects of the alleles of mlo/Mlo and the $7 \mathrm{H}$ resistance QTL, Rmoq1/rmoq1, against the MoT and $\mathrm{MoO}$ pathotypes (Tables 6 and 7). The experiment consisted of three consecutive series per blast isolate, and three seedlings per RIL per series. The results suggest the mlo allele to increase the level of susceptibility of RILs neither to MoT nor to MoO, and confirm again that the Rmoql gene is effective to MoT but not to the MoO.

\section{Discussion}

Host specificity of the blast pathogen

Our results show that the isolates collected on wheat can infect the majority of barley accessions with little difference between the cultivated and the wild ancestor barley. An isolate collected from rice could infect 
barley accessions to a similar degree as the isolates collected from wheat. However, none of the tested rice accessions was susceptible to the MoT isolate. This pathogenicity of wheat pathotypes on barley and rice but lack of pathogenicity of rice pathotypes on barley confirmed results obtained on much more limited sets of plant materials by Urashima et al. (1993) and Castroagudín et al. (2016). The results suggest that pathogenicity to rice and pathogenicity to wheat (and barley) require different gene(s) in the pathogen. Isolates may carry both sets of genes (to wheat and to rice: the $\mathrm{MoO}$ isolate) or only the gene(s) for pathogenicity to wheat and barley (the MoT isolate).

Sources of blast resistance in the barley gene pool

Wheat blast is an important endemic disease in South America and efforts have been made to determine sources of genetic resistance in the host species. So far only a few sources of blast resistance have been reported in the wheat gene pool (Prestes et al. 2007; Cruz et al. 2010; Cruz and Valent 2017). In the medium-sized collection of modern European barley cultivars tested in this study, nine percent of the cultivars were resistant to the wheat as well as to the rice isolates and 39 percent of the cultivars showed a pathotype- or isolate-specific type of resistance. We can conclude that the barley gene pool is a relatively rich source of blast resistance genes at the seedling stage. However it remains to be determined whether the barley accessions that are resistant at the seedling stage are also resistant at the adult plant stage under field conditions.

Polygenic resistance resulting in immunity

The resistance identified in accession CGN02857 was very interesting. We expected this complete resistance to inherit monogenically, like the many $R$-genes reported in rice against $M$. oryzae. However, in the $F_{2}$ CGN02857 $\times$ Vada we found a continuous and quantitative segregation for infection phenotype (Fig. 3e). The inheritance, therefore, should be considered quantitative. In a recent review, Niks et al. (2015) argued that in resistance there are two aspects the terms qualitative/quantitative may refer to: the phenotypic contrast and the inheritance. The resistance that we identified in accession CGN02857 to the wheat isolate of $M$. oryzae has an interesting and unusual combination of being phenotypically qualitative (complete), and genetically quantitative.

Isolate and pathotype specificity of QTLs for blast resistance in barley

Our test of a selected panel of barley accessions with a set of 10 Triticum isolates (Table 2) indicated substantial isolate specificity of the quantitative resistance. Therefore, the finding that Rmoq2 was effective against BR32, and not against PY67.1, was no surprise. Isolate-specific QTLs for blast resistance in barley have been already reported (Chen et al. 2003; Kongprakhon et al. 2009). Chen et al. (2003) identified twelve QTLs for blast resistance in barley against three rice blast isolates; one was effective to all three isolates, and the others were effective to only one or two of the isolates. The major effect QTL Rmoql was effective to both MoT isolates, but not to the MoO isolate GUY11. We should have tested more isolates per pathotype in order to separate pathotype specificity from isolate specificity. Therefore the results of QTL mapping for blast resistance in L/V against the MoT and the $\mathrm{MoO}$ isolates may indicate that blast resistance is under the control of few QTLs with isolate- and possibly also a pathotype-specific effect. This isolate and/or pathotype specificity is also supported by the association study, in which only one QTL out of 16 was associated with blast resistance to both the MoT and the MoO isolates. Kongprakhon et al. (2009). mapped a large-effect resistance QTL effective against two barley and two rice blast isolates. They also reported a QTL that was effective only against the two barley isolates and two other QTLs that were effective only against the two rice isolates.

Clustering of blast resistance QTL and powdery mildew resistance genes

Six out of 27 blast resistance QTLs mapped to the same genomic regions of barley as powdery mildew resistance genes. These co-localizations are interesting since in both barley-M.oryzae and barley- 
Blumeria graminis pathosystems resistance at the penetration stage is associated with the formation of cell wall appositions (papillae) (Aghnoum and Niks 2010; Zellerhoff et al. 2006). Inukai et al. (2006) identified four blast resistance QTLs in the BCD47 $\times$ Baronesse population against a rice blast isolate, of which three QTLs coincided with the positions of mildew resistance genes, Mla, mlo and Mlf on chromosome $1 \mathrm{H}, 4 \mathrm{H}$ and $7 \mathrm{H}$, respectively. Baronesse has the Mla3 powdery mildew resistance gene but neither Baronesse nor BCD47 have mlo and Mlf powdery mildew resistance genes, so, the resistance to blast at loci Mlo and Mlf may be due to susceptibility alleles to powdery mildew, or to different genes linked to them. Also Mlg and Mlhb mildew resistance loci and barley blast resistance QTLs have previously been reported to be associated, viz. in the Harrington $\times$ TR306 mapping population. Harrington carries the $\mathrm{Mlg}$ mildew resistance gene but the blast resistance QTL allele was contributed by TR306 (Chen et al. 2003; Sato et al. 2001). So, in case the association between blast and powdery mildew is real, the susceptibility alleles for mildew tend to confer increased resistance to blast.

Here, we found co-localization of blast resistance QTLs with Mla, mlo, Mlg, Mlhb, mlt and Mlj resistance genes. This is the first report of colocalization of blast resistance QTLs with mlt and $M l j$ genes. Further investigation is needed to dissect these co-localizations and to prove whether the same genes are responsible for resistance to both pathogens or different linked genes are involved and whether the resistance or the susceptibility alleles for powdery mildew confer resistance to the blast pathogen.

The non-race specific resistance in barley to the powdery mildew pathogen by recessive loss-of-function mlo mutant alleles has been reported to enhance the susceptibility against rice isolates of $M$. oryzae (e.g. Jarosch et al. 1999; Jansen et al. 2007), but there are no reports whether this association holds also true against blast isolates derived from other cultivated cereals including wheat. Jarosch et al. (1999) reported that on Mlo plants challenged by the blast pathogen, a higher proportion of attacked cells formed an effective papilla (about 44\%) to arrest cell wall penetration compared to an mlo-5 backcross line (11\%). Jansen et al., (2007) performed a mutational analysis in the mlo genetic background and identified an enhanced Magnaporthe resistance (emrl) mutant which shows restored resistance against $M$. oryzae. The emrl mutant retained effective mlo resistance against the barley powdery mildew pathogen, Blumeria graminis f.sp. hordei. Histological analysis showed that the restored resistance in emrl mutant against the blast pathogen is mainly based on formation of papillae at the sites of attempted penetration. In a similar work by Jansen and Schaffrath (2009), the emr2 (enhanced Magnaporthe resistance 2) mutant is reported in the mlo5 genetic background. Plants that carry the emr2 mutant allele showed enhanced resistance against $M$. oryzae and also against necrotrophic fungal pathogens, Drechslera teres and Rhynchosporium secalis, the causal agents of barley net blotch and scald diseases, but retained resistance to the powdery mildew pathogen. These studies indicate that the blast susceptibility enhancing effect of $m l o$ depends on the plant genetic background, such as alleles of Emr-like genes. Such genes in the background might explain the lack of susceptibility enhancing effect against the wheat infecting pathotype in our set of association mapping panel (Fig. 4), but cannot explain our lack of finding an effect of the L94 allele of mlo in the L/V mapping population (Tables 3, 6 and 7). Considering the hypothesis that mlo enhances blast susceptibility, we expected a QTL in the map region of the mlo gene on chromosome $4 \mathrm{H}$, but in the $\mathrm{L} / \mathrm{V}$ population $\mathrm{L} 94$ only contributed a susceptibility allele at $1 \mathrm{H}$, and not one at $4 \mathrm{H}$. All the reports on the role of the mlo gene on enhanced susceptibility to $M$. oryzae are based on comparison of reaction of barley back-cross lines carrying an mlo allele in the genetic background of $\mathrm{cv}$. Ingrid with $M l o$ wild-type plants. The reported role of mlo seems to be limited to the rice infecting pathotype (e.g. Jarosch et al. 1999; Jarosch et al. 2003; Jansen et al. 2007). In interactions of barley genotypes carrying the Mlo or mlo allele with non-adapted isolates of Magnaporthe originated from Pennisetum spp. (fontaingrass) or Digitaria (crabgrass) no macroscopic disease development was observed (Zellerhoff et al. 2006). Our results based on both the Triticum and the Oryza pathotypes cast some doubt on the general validity of the blast promoting effect of the mlo allele. 
Acknowledgements R. Aghnoum was supported by ERANET Plant Genomics (ERA-PG) funded TritNONHOST project. Anton Vels is gratefully acknowledged for his excellent technical assistance in the glasshouse experiments. We thank Dr. Didier Tharreau from CIRAD, France, Dr. Ulrich Schaffrath from the Institute of Plant Physiology, RWTH Aachen University, Germany and the Embrapa Trigo, Brazil for providing the Magnaporthe isolates used in this study. Euphytica foundation, Wageningen University and the European Cereal Atlas Fund (ECAF) are acknowledged for granting a subsidy for a short working visit to WUR to the first author. We are grateful to Prof. Richard Visser for arrangement of the Euphytica fund.

\section{Compliance with ethical standards}

Conflict of interest The authors declare that they have no conflict of interest.

Open Access This article is distributed under the terms of the Creative Commons Attribution 4.0 International License (http:// creativecommons.org/licenses/by/4.0/), which permits unrestricted use, distribution, and reproduction in any medium, provided you give appropriate credit to the original author(s) and the source, provide a link to the Creative Commons license, and indicate if changes were made.

\section{References}

Abu Sadat M, Choi J (2017) Wheat blast: a new fungal inhabitant to Bangladesh threatening world wheat production. Plant Pathol J 33:103-108

Aghnoum R, Niks RE (2010) Specificity and levels of nonhost resistance to nonadapted Blumeria graminis forms in barley. New Phytol 185:275-284

Aghnoum R, Marcel TC, Johrde A, Pecchioni N, Schweizer P, Niks RE (2010) Basal host resistance of barley to powdery mildew: connecting quantitative trait loci and candidate genes. Mol Plant Microbe Interact 1:91-102

Anh VL, Anh NT, Tagle AG, Vy TT, Inoue Y, Takumi S, Chuma I, Tosa Y (2015) Rmg8, a new gene for resistance to Triticum isolates of Pyricularia oryzae in hexaploid wheat. Phytopathology 105:1568-1572

Atienza SG, Jafary H, Niks RE (2004) Accumulation of genes for susceptibility to rust fungi for which barley is nearly a nonhost results in two barley lines with extreme multiple susceptibility. Planta 220:71-79

Babujee L, Gnanamanickam SS (2000) Molecular tools for characterization of rice blast pathogen, Magnaporthe grisea, population and molecular marker-assisted breeding for disease resistance. Curr Sci 78:248-257

Ballini E, Morel J-B, Droc G, Price A, Courtois B, Notteghem J-L, Tharreau D (2008) A genome-wide meta-analysis of rice blast resistance genes and quantitative trait loci provides new insights into partial and complete resistance. Mol Plant Microbe Interact 21:859-868
Castroagudín VL, Moreira SI, Pereira DAS, Moreira SS, Brunner PC, Maciel JLN, Crous PW, McDonald BA, Alves E, Ceresini PC (2016) Pyricularia graminis-tritici, a new Pyricularia species causing wheat blast. Persoonia Mol Phylogeny Evol Fungi 37:199-216

Chen H, Wang SP, Xing YZ, Xu CG, Hayes PM, Zhang QF (2003) Comparative analyses of genomic locations and race specificities of loci for quantitative resistance to Pyricularia grisea in rice and barley. Proc Natl Acad Sci USA 100:2544-2549

Couch BC, Kohn LM (2002) A multilocus gene genealogy concordant with host preference indicates segregation of a new species, $M$. oryzae, from $M$. grisea. Mycologia 94:683-693

Cruz CD, Valent B (2017) Wheat blast disease: danger on the move. Trop Plant Pathol 42:210-222

Cruz MFA, Prestes AM, Maciel JLN, Scheeren PL (2010) Partial resistance to blast on common and synthetic wheat genotypes in seedling and in adult plant growth stages. Trop Plant Pathol 35:24-31

Garris AJ, Tai TH, Coburn J, Kresovich S, McCouch S (2005) Genetic structure and diversity in Oryza sativa L. Genetics 169:1631-1638

Greer CA, Webster RK (2001) Occurrence, distribution, epidemiology, cultivar reaction, and management of rice blast disease in California. Plant Dis 85:1096-1102

Hyon G-S, Nga N, Chuma I, Inoue Y, Asano H, Murata N, Kusaba M, Tosa Y (2012) Characterization of interactions between barley and various host-specific subgroups of Magnaporthe oryzae and M. grisea. J Gen Plant Pathol 78(4):237-246

Inukai T, Vales MI, Hori K, Sato K, Hayes PM (2006) RMol confers blast resistance in barley and is located within the complex of resistance genes containing Mla, a powdery mildew resistance gene. Mol Plant Microbe Interact 19:1034-1041

Jafary H, Szabo LJ, Niks RE (2006) Innate nonhost immunity in barley to different heterologous rust fungi is controlled by sets of resistance genes with different and overlapping specificities. Mol Plant Microbe Interact 19:1270-1279

Jansen M, Schaffrath U (2009) The barley mutant emr2 shows enhanced resistance against several fungal leaf pathogens. Plant Breed 128:124-129

Jansen RC, Stam P (1994) High resolution of quantitative traits into multiple loci via interval mapping. Genetics 136:1447-1455

Jansen C, von Wettstein D, Schafer W, Kogel KH, Felk A, Maier FJ (2005) Infection patterns in barley and wheat spikes inoculated with wild-type and trichodiene synthase gene disrupted Fusarium graminearum. Proc Natl Acad Sci USA 102:16892-16897

Jansen M, Jarosch B, Schaffrath U (2007) The barley mutant emrl exhibits restored resistance against Magnaporthe oryzae in the hypersusceptible mlo-genetic background. Planta 225:1381-1391

Jarosch B, Kogel KH, Schaffrath U (1999) The ambivalence of the barley Mlo locus: mutations conferring resistance against powdery mildew (Blumeria graminis f.sp hordei) enhance susceptibility to the rice blast fungus Magnaporthe grisea. Mol Plant Microbe Interact 12:508-514 
Jarosch B, Jansen M, Schaffrath U (2003) Acquired resistance functions in mlo barley, which is hyper-susceptible to Magnaporthe grisea. Mol Plant Microbe Interact 16:107-114

Jørgensen JH (1992) Discovery, characterization and exploitation of Mlo powdery mildew resistance in barley. Euphytica 63:141-152

Kawai T, Kitamura Y, Ootani H, Watanabe K (1979) Studies on the cultivation of summer sown barley. 3. Peculiarity in the occurrence of diseases and insect pests. Shiga Pref Agric Exp Stat Rep 58:38-41

Király L, Kumar J, Hückelhoven R, Kogel KH (2002) mlo5, a resistance gene effective against a biotrophic pathogen (Blumeria graminis f.sp. hordei) confers enhanced susceptibility of barley to the necrotrophic fungus Bipolaris sorokiniana (teleomorph: Cochliobolus sativus). Acta Biol Szeged 46:135-136

Kohli MM, Mehta YR, Guzman E, De Viedma L, Cubilla LE (2011) Pyricularia blast: a threat to wheat cultivation. Czech J Genet Plant Breed 47:130-134

Kongprakhon P, Cuesta-Marcos A, Hayes PM, Richardson KL, Sirithunya P, Sato K, Steffenson B, Toojinda T (2009) Validation of rice blast resistance genes in barley using a QTL mapping population and near-isolines. Breed Sci 59:341-349

Kraakman ATW, Niks RE, Van den Berg PMMM, Stam P, Van Eeuwijk FA (2004) Linkage disequilibrium mapping of yield and yield stability in modern spring barley cultivars. Genetics 168:435-446

Kraakman ATW, Martínez F, Mussiraliev B, Eeuwijk FAV, Niks RE (2006) Linkage disequilibrium mapping of morphological, resistance, and other agronomically relevant traits in modern spring barley cultivars. Mol Breed $17: 41-58$

Kumar J, Hückelhoven R, Beckhove U, Nagarajan S, Kogel KH (2001) A compromised Mlo pathway affects the response of barley to the necrotrophic fungus Bipolaris sorokiniana (Teleomorph: Cochliobolus sativus) and its toxins. Phytopathology 91:127-133

Kurth J, Kolsch R, Simons V, Schulze-Lefert P (2001) A high resolution genetic map and a diagnostic RFLP marker for the $\mathrm{Mlg}$ resistance locus to powdery mildew in barley. Theor Appl Genet 102:53-60

Lima MIPM, Minella E (2003) Occurrence of head blast in barley. Fitopatol Bras 28:207

Lippert C, Listgarten J, Liu Y, Kadie CM, Davidson RI, Heckerman D (2011) Fast linear mixed models for genome-wide association studies. Nat Methods 8:833-835

Makepeace JC, Oxley SJP, Havis ND, Hackett R, Burke JI, Brown JKM (2007) Associations between fungal and abiotic leaf spotting and the presence of mlo alleles in barley. Plant Pathol 56:934-942

Matsumoto S, Mogi S (1979) Ear blast disease of late-summer sown barley (in Japanese). Proc Assoc Pl Prot Kyushu 25:12-14 (in Japanese)

McGrann GR, Stavrinides A, Russell J, Corbitt MM, Booth A, Chartrain L, Thomas WTB, Brown JKM (2014) A trade-off between mlo resistance to powdery mildew and increased susceptibility of barley to a newly important disease, $R a$ mularia leaf spot. J Exp Bot 65:1025-1037
Nga NTT, Inoue Y, Chuma I, Hyon G-S, Okada K, Vy TTP, Kusaba M, Tosa Y (2012) Identification of a novel locus Rmo2 conditioning resistance in barley to host-specific subgroups of Magnaporthe oryzae. Phytopathology 102:674-682

Niks RE (1987) Nonhost plant species as donors for resistance to pathogens with narrow host range I. Determination of nonhost status. Euphytica 36:841-852

Niks RE, Qi X, Marcel TC (2015) Quantitative resistance to biotrophic filamentous plant pathogens: concepts, misconceptions and mechanisms. Ann Rev Phytopathol 53:445-470

Oh HS, Tosa Y, Takabayashi N, Nakagawa S, Tomita R, Don LD, Kusaba M, Nakayashiki H, Mayama S (2002) Characterization of an Avena isolate of Magnaporthegrisea and identification of a locus conditioning its specificity on oat. Can J Bot 80:1088-1095

Pickering RA, Hill AM, Michel M, Timmerman-Vaughan GM (1995) The transfer of a powdery mildew resistance gene from Hordeum bulbosum L. to barley (H. vulgare L.) chromosome 2 (2I). Theor Appl Genet 91:1288-1292

Prestes AM, Arendt PF, Fernandes JMC, Scheeren PL (2007) Resistance to Magnaporthe grisea among Brazilian wheat genotypes. In: Buck HT, Nisi JE, Salomón N (eds) Wheat production in stressed environments. Springer, Dordrecht, pp 119-123

Qi X, Niks RE, Stam P, Lindhout P (1998) Identification of QTLs for partial resistance to leaf rust (Puccinia hordei) in barley. Theor Appl Genet 96:1205-1215

Sato K, Inukai T, Hayes PM (2001) QTL analysis of resistance to the rice blast pathogen in barley (Hordeum vulgare). Theor Appl Genet 102:916-920

Schönfeld M, Ragni A, Fischbeck G, Jahoor A (1996) RFLP mapping of three new loci for resistance genes to powdery mildew (Erysiphe graminis f.sp hordei) in barley. Theor Appl Genet 93:48-56

Sharma R, Upadhyaya HD, Manjunatha SV, Rai KN, Gupta SK, Thakur RP (2013) Pathogenic variation in the pearl millet blast pathogen, Magnaporthe grisea and identification of resistance to diverse pathotypes. Plant Dis 97:189-195

Skamnioti P, Gurr SJ (2009) Against the grain: safeguarding rice from rice blast disease. Trends Biotechnol 27:141-150

Tagle AG, Chuma I, Hisano H, Sato K, Tosa Y (2016) Genetic analysis of the resistance of barley to cryptic species of Pyricularia. J Gen Plant Pathol 82:302-306

Tufan HA, McGrann GRD, Magusin A, Morel JB, Miche L, Boyd LA (2009) Wheat blast: histopathology and transcriptome reprogramming in response to adapted and nonadapted Magnaporthe isolates. New Phytol $184: 473-484$

Urashima AS, Igarashi S, Kato H (1993) Host range, mating type, and fertility of Pyricularia grisea from wheat in Brazil. Plant Dis 77:1211-1216

Urashima AS, Lavorent NA, Goulart ACP, Mehta YR (2004) Resistance spectra of wheat cultivars and virulence diversity of Magnaporthe grisea isolates in Brazil. Fitopatol Bras 29:511-518

Varshney RK, Marcel TC, Ramsay L, Russell J, Röder MS, Stein N, Waugh R, Langridge P, Niks RE, Graner A (2007) A high density barley microsatellite consensus map with 775 SSR loci. Theor Appl Genet 114:1091-1103 
Yadav MK, Aravindan S, Ngangkham U, Shubudhi HN, Bag MK, Adak T et al (2017) Use of molecular markers in identification and characterization of resistance to rice blast in India. PLoS ONE. https://doi.org/10.1371/journal.pone. 0176236

Yaegashi H (1988) Inheritance of blast resistance in two-rowed barley. Plant Dis 72:608-610

Zellerhoff N, Jarosch B, Groenewald JZ, Crous PW, Schaffrath U (2006) Nonhost resistance of barley is successfully manifested against Magnaporthe grisea and a closely related Pennisetum-infecting lineage but is overcome by
Magnaporthe oryzae. Mol Plant Microbe Interact 19:1012-1022

Zhan SW, Mayama S, Tosa Y (2008) Identification of two genes for resistance to Triticum isolates of Magnaporthe oryzae in wheat. Genome 51:216-221

Publisher's Note Springer Nature remains neutral with regard to jurisdictional claims in published maps and institutional affiliations. 